\title{
European Monetary Union: A Cointegration Analysis
}

\author{
Alfred A. Haug \\ University of Canterbury \\ James G. MacKinnon
}

Queen's University

\section{Leo Michelis}

Ryerson University

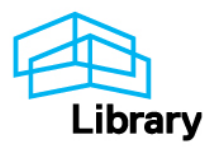




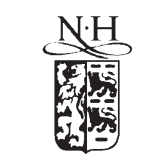

ELSEVIER
Journal of International Money and Finance 19 (2000) 419-432
Journal of

International

Money

and Finance

www.elsevier.n1/locate/econbase

\title{
European Monetary Union: a cointegration analysis
}

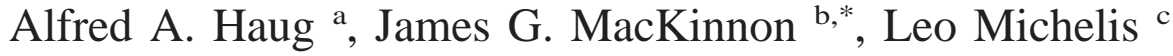 \\ ${ }^{a}$ Department of Economics, University of Canterbury and York University, Private Bag 4800, \\ Christchurch, New Zealand \\ ${ }^{\mathrm{b}}$ Department of Economics, Queen's University, Kingston, Ontario, Canada K7L $3 N 6$ \\ ${ }^{c}$ Department of Economics, Ryerson Polytechnic University, Toronto, Ontario, Canada M5B 2K3
}

\begin{abstract}
This paper employs systems-based cointegration techniques developed by Johansen (1998, Journal of Economic Dynamics and Control 12, 231-254; 1995, Likelihood-based Inference in Cointegrated Vector Autoregressive Models, Oxford University Press) to determine which European Union countries would form a successful Economic and Monetary Union (EMU), based on long-run behavior of the nominal convergence criteria laid down in the Maastricht treaty. The original 12 European Union countries are analyzed together. Nominal exchange rates, real exchange rates, long-term interest rates, and government budget deficits are each analyzed for co-movements among the 12 countries and various subgroups of them. The results suggest that not all of the 12 original countries of the European Union can form a successful EMU over time, unless several countries make significant adjustments. (C) 2000 Elsevier Science Ltd. All rights reserved.
\end{abstract}

JEL classification: F42; F33

\section{Introduction}

The European Economic and Monetary Union (EMU) represents the third and final stage of a complete economic and monetary union among the countries participating in the European Union (EU), namely, Belgium, Denmark, France, Germany, Greece, Ireland, Italy, Luxembourg, the Netherlands, Portugal, Spain and the United Kingdom. In addition to these countries, Austria, Finland and Sweden have recently

* Corresponding author. Tel.: +1-613-533-2293; fax: +1-613-533-2257.

E-mail address: jgm@qed.econ.queensu.ca (J.G. MacKinnon). 
joined the EU. The legal, institutional and monetary aspects of European integration were laid down in the Maastricht Treaty (1992), following the recommendations of the Delors Report (1989); see also Eichengreen and Wyplosz (1993).

Regarding the monetary and fiscal aspects of the treaty, four "nominal convergence" criteria were laid down that would have to be met by a member country in order to qualify for participation in the EMU. These were:

(a) no devaluation of its currency in the 2 years preceding the entrance into the union;

(b) inflation rate no higher than $1.5 \%$ above the average of the three countries with the lowest inflation rates;

(c) long-term interest rate not in excess of $2 \%$ above the average of the three countries with the lowest inflation rates; and

(d) government deficits and debts not exceeding $3 \%$ and $60 \%$ of the GDP, respectively.

Since the late 1970 s, monetary and, to some extent, fiscal policy coordination among the EU member countries has been the focus of the European Commission's efforts. Tight monetary policies can contribute to inflation convergence, and fiscal austerity may foster convergence of long-term interest rates and reductions in budget deficits and debts over time, thus leading to exchange rate stability. In addition, the Exchange Rate Mechanism (ERM) of the European Monetary System (EMS) was introduced in March of 1979 to provide intra-EMS exchange rate stability.

Several studies in the literature have provided empirical evidence about these nominal "convergence" criteria. Artis and Taylor (1988) found that the ERM exerted a short run stabilizing effect on intra-EMS exchange rates. Karfakis and Moschos (1990) used the Engle and Granger (1987) bivariate cointegration framework to test for interest rate linkages between Germany and each of the countries: Belgium, France, Ireland, Italy and the Netherlands. Using monthly data over the period from April 1979 to November 1988, they found no cointegration in the pairs of interest rates. MacDonald and Taylor (1991) used Johansen's (1988) method and presented evidence of long run partial co-movement in real and nominal exchange rates and in money supplies. They considered three EMS countries over the period 1979-1988. They did not include other variables in their study. Similarly, Hafer and Kutan (1994) adopted the multivariate cointegration framework to test for co-movements of shortterm interest rates and money supplies among Belgium, France, Germany, Italy and the Netherlands. Using monthly data over the period from March 1979 to December 1990, they found evidence of partial policy convergence among these countries. Based on conditional variance comparisons and persistence of real exchange rate shocks, von Hagen and Neumann (1994) reported results supportive of the idea of a two-speed Europe, with Germany, its smaller neighbors (including Austria), and France forming a viable monetary union. Bayoumi and Taylor (1995) examined the comparative behavior of real output growth and inflation rates of ERM and nonERM participants and concluded that the ERM has contributed to macro-policy coordination among ERM members. Hafer et al. (1997) used multivariate cointegration 
techniques to test for the link among interest rate term structures for a selected group of EU countries. Using monthly data from March 1979 to June 1995, they found co-movements in the common trends in the term structures over time. Their results support the view that Germany will not dominate the proposed EMU.

Our study makes two new contributions to the literature. First, we consider, as far as data are available, all of the 12 original EU countries and try to analyze all the criteria of the Maastricht Treaty. Like other researchers, we employ the multivariate cointegration framework for our analysis. In view of the fact that the macroeconomic variables involved in the four nominal criteria are typically integrated of order one, a minimum and necessary requirement for the formation of a successful EMU over time is the existence of stable long-run relationships that tie together the variables in each criterion. Otherwise, the chances for long-run success of an EMU would be slim. This issue is the focus of our paper. We use Johansen's $(1988,1991,1995)$ likelihood-based technique for cointegrated vector autoregressive models. If the variables for the EU countries are found to be cointegrated within each of the four criteria, deviations from certain linear combinations will be stationary, implying that the variables will be tied together in the long run. Because the nominal convergence criteria imply co-movement of specific variables over time, the cointegration approach is well-suited to assess the potential of an EMU.

Second, our statistical inferences on cointegration will be based on highly accurate numerical approximations to the distributions of the test statistics, based on extensive simulations using response surface methodology. The details of these simulations are available in MacKinnon et al. (1999). One major finding from that paper is that critical values for the Trace and $\lambda_{\max }$ tests obtained by the response surface approach are quite different from the critical values that are used routinely in applied work, such as those in Osterwald-Lenum (1992). This is especially true when the dimension of the multivariate system is large (i.e. exceeding the values of five or six). Since in the present study we deal mostly with large systems involving 10, 11, or even 12 variables at once, our numerical distributions are indispensable for correct asymptotic inference.

In Section 2, we outline the models and the test statistics that will be used in the paper. A brief description of the response surface methodology is also offered in this section. In Section 3, we describe the data and we present and discuss the empirical results. Looking ahead, our results support only a partial convergence of policies among the 12 EU countries. This implies that not all the 12 original EU countries could be part of a successful EMU over time without possibly painful adjustments in the long-run.

\section{The cointegration models and test statistics}

The maximum likelihood theory of systems of potentially cointegrated stochastic variables presupposes that the variables are integrated of order one, or $I(1)$, and that the data generating process is a Gaussian vector autoregressive model of finite order $k$, or $\operatorname{VAR}(k)$, possibly including some deterministic components. Let $\mathbf{X}_{t}$ be a $p$ - 
dimensional column vector of $I(1)$ variables. Following Johansen (1995), the VAR $(k)$ model can be written in VECM (vector error-correction model) form as

$$
\Delta \mathbf{X}_{t}=\boldsymbol{\Pi} \mathbf{X}_{t-1}+\sum_{i=1}^{k-1} \boldsymbol{\Gamma}_{i} \Delta \mathbf{X}_{t-i}+\boldsymbol{\mu}_{0}+\boldsymbol{\mu}_{1} t+\mathbf{U}_{t}, t=1, \ldots, T
$$

where $\boldsymbol{\Pi}$ and the $\boldsymbol{\Gamma}_{i}$ are $p \times p$ matrices of coefficients, and $\boldsymbol{\mu}_{0}$ and $\boldsymbol{\mu}_{1}$ are $p \times 1$ vectors of constant and trend coefficients, respectively. It will be convenient to let $\boldsymbol{\mu}_{t} \equiv \boldsymbol{\mu}_{0}+\boldsymbol{\mu}_{1} t$ denote the deterministic part of the model. The error vector $\mathbf{U}_{t}$, which is $p \times 1$, is assumed to be multivariate normal with mean vector zero and covariance matrix $\boldsymbol{\Omega}$, and to be independent across time periods.

The VECM representation in Eq. (1) is convenient because the hypothesis of cointegration can be stated in terms of the long run impact matrix, П. This matrix can always be written as

$$
\Pi=\boldsymbol{\alpha} \boldsymbol{\beta}^{\prime}
$$

where $\boldsymbol{\alpha}$ and $\boldsymbol{\beta}$ are $p \times r$ matrices of full rank. If $r=0$, then $\boldsymbol{\Pi}=\mathbf{0}$, and there exists no linear combination of the elements of $\mathbf{X}_{t}$ that is stationary. At the other extreme, if $\operatorname{rank}(\boldsymbol{\Pi})=p, \mathbf{X}_{t}$ is a stationary process. In the intermediate case, when $0<r<p$, there exist $r$ stationary linear combinations of the elements of $\mathbf{X}_{t}$, along with $p-r$ stochastic trends.

Under the hypothesis given in Eq. (2), the relation between $\boldsymbol{\alpha}$ and the deterministic term $\boldsymbol{\mu}_{t}$ is crucial in determining the properties of the process $\mathbf{X}_{t}$ and the various cases of interest that can arise. Consider the decomposition of $\boldsymbol{\mu}_{0}$ and $\boldsymbol{\mu}_{1}$ in the directions $\boldsymbol{\alpha}$ and $\boldsymbol{\alpha}_{\perp}$, where $\boldsymbol{\alpha}_{\perp}$ is a $p \times(p-r)$ matrix orthogonal to $\boldsymbol{\alpha}$. We can write

$$
\boldsymbol{\mu}_{i}=\boldsymbol{\alpha} \boldsymbol{\beta}_{i}+\boldsymbol{\alpha}_{\perp} \boldsymbol{\gamma}_{i}, i=0,1
$$

where $\boldsymbol{\beta}_{i}=\left(\boldsymbol{\alpha}^{\prime} \boldsymbol{\alpha}\right)^{-1} \boldsymbol{\alpha}^{\prime} \boldsymbol{\mu}_{i}$ and $\boldsymbol{\gamma}_{i}=\left(\boldsymbol{\alpha}_{\perp}{ }^{\prime} \boldsymbol{\alpha}_{\perp}\right)^{-1} \boldsymbol{\alpha}_{\perp}{ }^{\prime} \boldsymbol{\mu}_{i}$. Different restrictions on $\boldsymbol{\mu}_{0}$ and $\boldsymbol{\mu}_{1}$ imply different submodels of the general model given in Eq. (1). Following Osterwald-Lenum (1992), we consider five submodels, which are ordered from most to least restrictive:

Case 0: $\boldsymbol{\mu}_{t}=\mathbf{0}$;

Case $1 *: \boldsymbol{\mu}_{t}=\boldsymbol{\alpha} \boldsymbol{\beta}_{0}$

Case 1: $\boldsymbol{\mu}_{t}=\boldsymbol{\mu}_{0}$;

Case $2 *: \boldsymbol{\mu}_{t}=\boldsymbol{\mu}_{0}+\boldsymbol{\alpha} \boldsymbol{\beta}_{1} t$

Case 2: $\boldsymbol{\mu}_{t}=\boldsymbol{\mu}_{0}+\boldsymbol{\mu}_{1} t$.

The interpretation of each of these models becomes clear by considering the solution of $\mathbf{X}_{t}$ in Eq. (1) using a version of the Granger Representation Theorem; see Johansen (1991, Theorem 4.1). Let $\mathbf{W}_{t}$ denote a stationary process, $\mathbf{A}$ denote a vector such that $\boldsymbol{\beta}^{\prime} \mathbf{A}=\mathbf{0}$, and $\mathbf{C}=\boldsymbol{\beta}_{\perp}\left(\boldsymbol{\alpha}_{\perp}{ }^{\prime} \boldsymbol{\Gamma} \boldsymbol{\beta}_{\perp}\right)^{-1} \boldsymbol{\alpha}_{\perp}{ }^{\prime}$, where $\boldsymbol{\Gamma}=\mathbf{I}_{p}-\sum_{\mathrm{i}=1}^{\mathrm{k}-1} \boldsymbol{\Gamma}_{i}$ and $\boldsymbol{\beta}_{\perp}$ is a $p \times(p-r)$ matrix of full rank orthogonal to $\boldsymbol{\beta}$. Then this solution is

$$
\mathbf{X}_{t}=\mathbf{C} \sum_{i=1}^{t} \mathbf{U}_{i}+\frac{1}{2} \boldsymbol{\tau}_{2} t^{2}+\boldsymbol{\tau}_{1} t+\boldsymbol{\tau}_{0}+\mathbf{W}_{t}+\mathbf{A}
$$


where $\boldsymbol{\tau}_{2}=\mathbf{C} \boldsymbol{\mu}_{1}$. The representation of Eq. (4) makes it clear that, in general, the inclusion of a linear time trend in Eq. (1) gives rise to a quadratic time trend in the process $\mathbf{X}_{t}$.

The five submodels describe different behaviors of the process $\mathbf{X}_{t}$ and the cointegrating relations $\boldsymbol{\beta}^{\prime} \mathbf{X}_{t}$. In Case $0, \mathbf{X}_{t}$ has no deterministic terms and all the stationary components have zero mean. In Case $1^{*}, \mathbf{X}_{t}$ has neither a quadratic trend, since $\boldsymbol{\mu}_{1}=\mathbf{0}$ and hence $\boldsymbol{\tau}_{2}=\mathbf{C} \boldsymbol{\mu}_{1}=\mathbf{0}$, nor a linear trend, since $\boldsymbol{\alpha}_{\perp}{ }^{\prime} \boldsymbol{\mu}_{0}=\mathbf{0}$ and hence $\boldsymbol{\tau}_{1}$, which is equal to $\mathbf{C} \boldsymbol{\mu}_{0}$ in this case, is equal to $\mathbf{0}$; see Johansen (1994, 1991, Theorem 4.1). However, both $\mathbf{X}_{t}$ and the cointegrating relations, $\boldsymbol{\beta}^{\prime} \mathbf{X}_{t}$, are allowed a constant term. In Case 1 , where $\boldsymbol{\alpha}_{\perp}{ }^{\prime} \boldsymbol{\mu}_{0} \neq \mathbf{0}$, we have $\boldsymbol{\tau}_{1} \neq \mathbf{0}$, and $\mathbf{X}_{t}$ therefore has a linear trend. This trend is eliminated in the cointegrating relations $\boldsymbol{\beta}^{\prime} \mathbf{X}_{t}$ because $\boldsymbol{\beta}^{\prime} \boldsymbol{\tau}_{1}=\boldsymbol{\beta}^{\prime} \mathbf{C} \boldsymbol{\mu}_{0}=\mathbf{0}$; see the definition of $\mathbf{C}$ preceding Eq. (4). In Case $2^{*}, \mathbf{X}_{t}$ has no quadratic trend since $\boldsymbol{\alpha}_{\perp}{ }^{\prime} \boldsymbol{\mu}_{1}=\mathbf{0}$ and hence $\boldsymbol{\tau}_{2}=\mathbf{0}$, but $\mathbf{X}_{t}$ has a linear trend which is present even in the cointegrating relations. Finally, Case 2 allows for a quadratic trend in the process $\mathbf{X}_{t}$, because $\boldsymbol{\mu}_{1} \neq \boldsymbol{0}$ and hence $\boldsymbol{\tau}_{2} \neq \mathbf{0}$. However, the cointegrating relations have a linear trend only, because $\boldsymbol{\beta}^{\prime} \boldsymbol{\tau}_{2}=\boldsymbol{\beta}^{\prime} \mathbf{C} \boldsymbol{\mu}_{1}=\mathbf{0}$.

Because of the normality assumption, it is natural to test for the reduced rank of II by using a likelihood ratio test. The procedure uses the technique of reduced rank regression first introduced by Anderson (1951) and applied to systems of I(1) variables independently by Johansen (1988) and Ahn and Reinsel (1990). This technique is appealing because it delivers at once the MLE of $\boldsymbol{\alpha}$ and $\boldsymbol{\beta}$ and the eigenvalues needed to construct likelihood ratio tests. Consider the problem of testing the null hypothesis that there are at most $r$ cointegrating vectors against the unrestricted model (see Eq. (1)). The null hypothesis is that $\operatorname{rank}(\boldsymbol{\Pi})=r$ and the alternative is that $\operatorname{rank}(\boldsymbol{\Pi})=p$. The likelihood ratio test statistic, called the Trace statistic by Johansen and Juselius (1990), is given by

$$
\text { Trace }=-T \sum_{i=r+1}^{p} \log \left(1-\lambda_{i}\right)
$$

where the $\lambda_{i}$ are the eigenvalues, ordered from smallest to largest, which arise in the solution of the reduced rank regression problem. The testing is performed sequentially either for $r=p-1, \ldots, 0$ or for $r=0, \ldots, p-1$. The testing sequence terminates when the null is rejected for the first time in the former case or when it is not rejected for the first time in the latter case. It is also possible to test the null that $\operatorname{rank}(\boldsymbol{\Pi})=r$ against the alternative that $\operatorname{rank}(\boldsymbol{\Pi})=r+1$. In that case, the likelihood ratio statistic, which is called the $\lambda_{\max }$ statistic, is

$$
\lambda_{\max }=-T \log \left(1-\lambda_{r+1}\right)
$$

Of course, the $\lambda_{\max }$ statistic is equal to the Trace statistic when $p-r=1$.

The asymptotic distributions of the test statistics in Eqs. (5) and (6) are nonstandard. They are given by the trace and maximal eigenvalue, respectively, of the expression 


$$
\int_{0}^{1} \mathrm{~d} \mathbf{B} \mathbf{F}^{\prime}\left[\int_{0}^{1} \mathbf{F} \mathbf{F}^{\prime} \mathrm{d} u\right]^{-1} \int_{0}^{1} \mathbf{F} \mathrm{d} \mathbf{B}^{\prime}
$$

where $\mathbf{B}$ is a standard $(p-r)$-dimensional Brownian motion on the unit interval and $\mathbf{F}$ depends on $\mathbf{B}$ and on which restrictions are imposed on the deterministic terms. For each case, Eq. (7) is independent of nuisance parameters and depends only on $p-r$.

In the literature, asymptotic critical values for the Trace and $\lambda_{\max }$ statistics in Eqs. (5) and (6) have been calculated by Monte Carlo simulations of Eq. (7), where B is approximated by a $(p-r)$-dimensional discrete random walk, generally with 400 steps. However, as we showed in MacKinnon et al. (1999), using this approach leads to quite inaccurate results, especially when $p-r$ is large. In that study, we computed either the test statistics in Eqs. (5) and (6) or approximations to Eq. (7) using simulated data for a number of sample sizes and then employed response surface regressions to estimate the quantiles of the asymptotic distributions.

For convenience, in this paper we will employ $P$ values to test for cointegration. Thus, the decision rule will be to reject the null of, say, $r=r_{0}$ cointegrating vectors if the estimated $P$ value is less than the preassigned level of significance of the test. Further, we will be testing the null sequentially from low to high values of $r$. Consequently, the testing sequence will terminate when the null is not rejected for the first time.

\section{Data and empirical results}

We analyze the behavior of the monthly nominal spot exchange rates per European Currency Unit (ECU) and per German Mark (DM). Inflation rates based on the consumer price index (CPI) seem to be mostly integrated of order one, or $I(1)$, for the countries considered. However, there are important exceptions; see Table 1. The concept of cointegration therefore does not apply to all countries considered, and we therefore analyze instead real monthly DM exchange rates derived using the CPI. We also study long-term interest rates, using monthly long-term government bond yields, and deficit/GDP ratios, using quarterly data because monthly data for deficits are not available. We do not study quarterly debt/GDP ratios because the data are not available for most of the countries considered in our study.

For the interpretation of the empirical results, we will claim "complete" convergence of government policies among a set of $p$ countries if we find $p-1$ cointegrating vectors and a single shared common stochastic trend. Otherwise, if $r$ is found to be in the interval $0<r<p-1$ we shall say that only "partial" convergence of policies has been achieved. This is the definition of convergence of policies as used by Hafer and Kutan, among others, in the context of cointegration of variables across countries. Convergence in this context implies that policies have been aligned enough so that the variables move towards an equilibrium in the long run and do not drift too far apart over time. The intuition of this terminology is as follows. If there exist two or more shared common stochastic trends in some policy measure of a given group 
Table 1

Augmented Dickey-Fuller tests for a unit root $^{\mathrm{a}}$

\begin{tabular}{lclllll}
\hline Country & ECU ex. rates Nom. DM ex. & $\begin{array}{l}\text { Real DM ex. } \\
\text { rates }\end{array}$ & Interest rates & $\begin{array}{l}\text { Deficit/GDP } \\
\text { ratios }\end{array}$ & Inflation \\
\hline Belgium & $-0.87(0.80)$ & $-2.29(0.18)$ & $-2.13(0.23)$ & $-0.99(0.76)$ & & $-0.99(0.76)$ \\
Denmark & $-0.81(0.81)$ & $-2.58(0.10)$ & $-1.73(0.41)$ & $-2.30(0.17)$ & & $-2.29(0.18)$ \\
France & $-2.12(0.24)$ & $-2.51(0.11)$ & $-1.41(0.58)$ & $-1.05(0.73)$ & $-2.72(0.08)$ & $-1.89(0.34)$ \\
Germany & $-0.91(0.78)$ & & & $-1.87(0.35)$ & $-2.36(0.16)$ & $-1.87(0.35)$ \\
Greece & $-1.22(0.67)$ & $-1.19(0.68)$ & $-2.78(0.06)$ & & & $-1.68(0.44)$ \\
Ireland & $-1.13(0.70)$ & $-0.56(0.88)$ & & $-1.48(0.54)$ & & \\
Italy & $0.17(0.97)$ & $0.05(0.96)$ & $-1.06(0.73)$ & $-1.72(0.42)$ & $-2.96(0.04)$ & $-2.53(0.11)$ \\
Luxembourg-0.87(0.80) & & $-2.22(0.20)$ & $-1.01(0.75)$ & & $-3.69(0.00)$ \\
Netherlands $-0.49(0.45)$ & $-2.68(0.08)$ & $-0.85(0.80)$ & $-1.56(0.50)$ & $-0.56(0.87)$ & $-2.04(0.27)$ \\
Portugal & $-2.04(0.27)$ & $-2.04(0.27)$ & $-2.01(0.28)$ & $-1.36(0.60)$ & & $-2.98(0.04)$ \\
Spain & $-1.50(0.53)$ & $-1.43(0.57)$ & $-1.55(0.51)$ & $-2.13(0.23)$ & $-3.87(0.00)$ & $-1.66(0.45)$ \\
UK & $-0.69(0.85)$ & $-0.31(0.92)$ & $-2.09(0.25)$ & $-1.51(0.53)$ & $-1.44(0.56)$ & $-4.27(0.00)$ \\
\hline
\end{tabular}

a The first entry in each cell is the ADF statistic. The second entry, in parentheses, is the associated $P$ value, calculated using the program of MacKinnon (1996). For the variables in the six columns of the table, the sample sizes are 193, 197, 195, 193, 60, and 195, respectively. We also tested the null of a second unit root. This hypothesis was rejected in all cases.

of EU countries, then it must be the case that some countries in the group set their policies independently, at least in the long run. Hence the circumstances of forming and maintaining an economic and monetary union will be quite difficult. On the other hand, finding only one shared common trend means that a multitude of policy measures have converged to a single common long-run path, dominated perhaps by the policy preferences of some country in the union.

Most of the data were taken from the IFS CD-ROM (International Monetary Fund, 1995). We collected data for all of the 12 original EU countries. The time periods considered are determined by the availability of data. When possible, we start in 1979:3, when the ERM was introduced. All exchange rates and interest rates are expressed in natural logarithms for our regressions. Monthly end-of-period nominal ECU rates are taken from the IFS, line ea (or line ec if line ea is not available). ECU rates for Greece and Portugal are not available prior to 1981:1 and 1985:7, respectively. We used ECU rates per US dollar and US dollar spot rates for these two countries to construct ECU rates for the months with missing data. ECU data cover the period from 1979:7 to $1995: 7$. Monthly nominal end-of-period spot exchange rates per US dollar are from the IFS, line ae (or line ag if line ae is not available; line ag is the inverse of line ae). The period covered is from 1979:3 to 1995:7. These US dollar spot exchange rates are used to calculate nominal DM exchange rates over the same period. Real DM exchange rates are constructed from the nominal DM exchange rates and the monthly CPI from line 64 in the IFS. The period considered is from 1979:3 to 1995:5. Monthly average long-term government bond yields are from the IFS, line 61, except for Denmark. This IFS data series was incomplete for Denmark and we therefore used the corresponding data from the 
OECD Main Economic Indicators that reports end-of-month figures instead of averages. The period covered is from 1979:3 to 1995:3.

Complete quarterly government deficit (or surplus) data are available only for a few countries: France, Germany, Italy, the Netherlands, Spain, and the UK. The data were obtained from the IFS, line 80. To construct the deficit/GDP ratios, we used quarterly GDP from the IFS, line 99b. Data are available from 1979:3 to 1994:2. For Italy, the years from 1991:4 to $1994: 2$ were missing and we used national debt figures from various issues of the Bolletino Mensile di Statistica, Institute Nazionale di Statistica in order to construct surplus figures from the quarterly change in debt. A comparison for earlier years shows that surpluses constructed from these debt figures are very close to the corresponding figures from the IFS.

Before estimating any VECM, we tested each time series for a unit root, using augmented Dickey-Fuller tests at the 5\% level of significance. Results are presented in Table 1. We employed Akaike's information criterion to select the appropriate lag lengths (see $\mathrm{Ng}$ and Perron, 1995) and then calculated $P$ values using a program developed in MacKinnon (1996) and available from the author's web site.

For most of the series, we are unable to reject the unit root hypothesis, but there are some exceptions. In particular, the CPI-based inflation rate appears to be $I(0)$ for Luxembourg, Portugal, and the UK. For this reason, no cointegration analysis was carried out for the inflation rates and the focus was instead on real CPI-based DM exchange rates. Also, for deficit/GDP ratios, we excluded Spain because this ratio seems to be $I(0)$. We consider the model with and without Italy because the test statistic for Italy is very close to the $5 \%$ critical value. In addition to the unit root tests reported in Table 1, we graphed inflation rates for Luxembourg, Portugal and Spain, and the deficit/GDP ratio for Spain. We further calculated autocorrelation and partial autocorrelation functions. All are not indicative of non-stationary processes. In particular, the autocorrelations taper off relatively quickly and do not have long tails typical of $I(1)$ processes. Also, the partial autocorrelations do not have spikes at the first lag with a value near one.

Table 2 reports the estimated $P$ values for the Trace and $\lambda_{\max }$ tests for ECU exchange rates, nominal DM exchange rates, real DM exchange rates, long-term interest rates, and deficit/GDP ratios. We set up a separate VECM for each one of these variables and used the Schwarz criterion to select the appropriate lag lengths; see Reimers (1993). Each VECM involves the largest set of the 12 original EU countries for which data are available.

We consider for the VECM model Case 0 , Case $1^{*}$, Case 1 , Case $2 *$, and Case 2, as described in Section 2. We first determined the number of cointegrating vectors, $r$, in each system and then tested the various submodels. In order to decide which submodel to use, we tested the various submodels against each other using likelihood ratio tests, which are distributed as $\chi^{2}$; see Johansen and Juselius (1990, Section 4.1). For all but one of the systems, we found that Case 0 is appropriate. The exception is interest rates in Table 2, for which Case $1^{*}$ seems to be appropriate. Results are presented in Tables 2 and 3. The use of asymptotic $P$ values makes it easy to present results for several VECM systems in only two tables.

We discuss the results for exchange rates first. We included all 12 countries for 


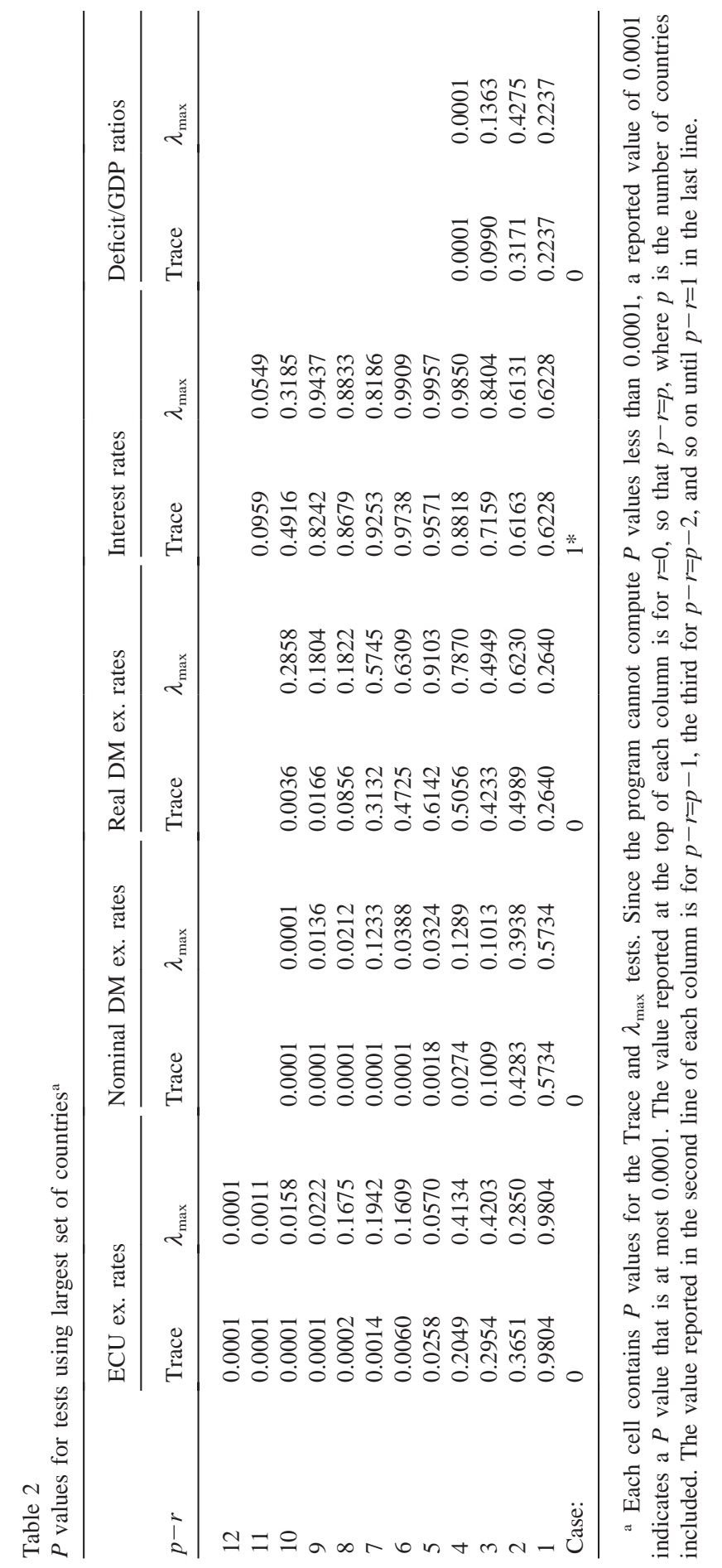


Table 3

$P$ values for tests using subsets of countries ${ }^{\mathrm{a}}$

\begin{tabular}{|c|c|c|c|c|}
\hline$p-r$ & $\begin{array}{l}\text { Real D } \\
\text { Trace }\end{array}$ & $\lambda_{\max }$ & $\begin{array}{l}\text { Interest } \\
\text { Trace }\end{array}$ & $\lambda_{\max }$ \\
\hline 8 & & & 0.0136 & 0.0097 \\
\hline 7 & 0.0085 & 0.0356 & 0.2759 & 0.2473 \\
\hline 6 & 0.1151 & 0.0298 & 0.6301 & 0.6856 \\
\hline 5 & 0.7050 & 0.7205 & 0.7611 & 0.9488 \\
\hline 4 & 0.7959 & 0.5522 & 0.6424 & 0.7287 \\
\hline 3 & 0.9570 & 0.9641 & 0.6660 & 0.8240 \\
\hline 2 & 0.8474 & 0.7886 & 0.4847 & 0.4327 \\
\hline 1 & 0.9429 & 0.9429 & 0.6527 & 0.6527 \\
\hline Case: & 0 & & 0 & \\
\hline
\end{tabular}

a See the note to Table 2 .

ECU rates. For DM rates, Germany had to be deleted, and we also excluded Luxembourg because its nominal exchange rate was fixed to Belgium's. Thus 10 countries were included in the system for DM rates. Based on the $P$ values in Table 2, we decisively reject the null hypothesis of no cointegration (which states that $r$, the number of cointegrating vectors, is equal to zero) for both nominal exchange rate systems. If we use a 5\% level of significance, the Trace test leads us to find eight cointegrating vectors for the ECU rates and seven vectors for the DM rates. With the $\lambda_{\max }$ test, we find fewer cointegrating vectors, four for the ECU rates and three for the DM rates.

We conclude that nominal exchange rates among the EU countries are cointegrated no matter which exchange rate definition is used. However, our empirical results indicate only partial convergence of fiscal and monetary policies among the EU countries. Since there are 12 ECU rates and 10 nominal DM rates, the Trace test results imply that there are four and three shared stochastic trends, respectively, in each system of exchange rates. This suggests that some EU countries follow policies that are independent of the policies followed by other member countries and changes have to be made to be consistent in the long-run with EMU. If a successful EMU over time is to be achieved, eventually, with all the 12 original members included, adjustments will have to be made.

For the real DM exchange rate, we had to exclude Ireland because the CPI was not available on a monthly basis, leaving us with real DM exchange rates for 10 EU countries. For this system, the Trace test detects two cointegrating vectors, but the $\lambda_{\max }$ test detects none. For long-term interest rates, we had to exclude Greece because data were not available, leaving us with 11 countries. For this system, neither test found cointegration at the $5 \%$ level, although the $\lambda_{\max }$ test came close. Finally, the last column of Table 2 reports results for the deficit/GDP ratio for France, Germany, the Netherlands, and the UK. Spain and Italy were excluded because their series appeared to be $I(0)$. Adding Italy (for which the unit root test was inconclusive) did not affect the test results. We find that both cointegration tests detect one cointe- 
grating vector for this 4-dimensional system. Thus, based on the results of the Trace test, we observe eight, 11, and three shared common trends in the systems of real DM exchange rates, long-term interest rates, and deficit/GDP ratios, respectively.

These results are not very encouraging for the success of an EMU among the 12 original EU countries. Nonetheless, the results point to the need for reform in government policies to achieve greater co-movement. Since all three criteria are likely to be affected by fiscal reforms, changes seem to be particularly desirable in this area. For instance, harmonization of tax and expenditure policies across countries, along with monetary reforms and other changes such as free mobility of capital and labor in the EU, should increase the prospects for an EMU among the original 12 countries by reducing the number of shared common trends and thereby increasing the number of cointegrating relations.

An alternative interpretation of the empirical results was suggested by an anonymous referee, who argued that convergence may not have been detected because it has occurred only recently. Consider, for instance, the deficit/GDP ratios for Italy and Germany. In the late 1980s, Italy's ratio was higher than Germany's. Therefore, during the early 1990s, Italy has been adjusting its fiscal policy to achieve convergence to the lower German ratio. Since the period from 1990 on represents only a part of our sample, it may not be long enough for us to detect convergence of fiscal policies.

This is certainly a possibility, but there is not yet enough evidence to regard it as any more than that. In an important sense, fiscal policy convergence is harder to achieve than monetary policy convergence because of the extra political constraints associated with fiscal policy reforms. Different countries have different legislative approaches to changes in fiscal policy, and some countries have traditionally preferred higher rates of government spending than others. Consequently, observing a deficit reduction in certain countries over a short period of time does not mean that it will be sustained in the future. For these reasons, we doubt that deficit reductions in recent years in some European countries are permanent. To put it differently, we doubt that these reductions are structural changes in the cointegration rank $r$ going from zero to a higher number in the post-1990 period. The sample from 1990 onwards is, unfortunately, too small to test this proposition formally.

In Table 3, we examine subgroups of EU countries for the real DM exchange rates and the long-term interest rates that we found in Table 2 not to be cointegrated among the full set of EU members. For the real DM rates, we use the evidence supplied by the $\lambda_{\max }$ test. The largest subgroup that leads to cointegration for real DM exchange rates consists of seven countries: Belgium, Denmark, France, Greece, Luxembourg, the Netherlands, and the UK. The Trace test finds a single shared common trend driving the long-run relationship among the seven real DM exchange rates. Hence, in this case, there appears to be complete convergence of government policies. Adding Portugal or Spain does not increase the number of cointegrating vectors. For long-term interest rates, we find cointegration among eight countries: Belgium, Denmark, France, Germany, Ireland, Luxembourg, the Netherlands, and the UK. Here, both tests detect a single shared common trend in the 8-dimensional 
system of long-term interest rates. Thus, in this case too, complete policy convergence among the eight EU countries can be claimed.

The need to use accurate critical values for the cointegration tests can be demonstrated by two examples. For interest rates in Table 2 when $p-r=11$, a $P$ value of 0.0549 is recorded for the $\lambda_{\max }$ test. In contrast, the $P$ value would be smaller than 0.05 according to the tables in Osterwald-Lenum because the $\lambda_{\max }$ statistic has a value of 70.8978 and Osterwald-Lenum reports a 5\% critical value of 69.74 and a $2.5 \%$ value of 72.64. Further, for the real DM exchange rates in Table 3, the $P$ value is 0.1151 for the Trace test statistic with a value of 78.5703. Osterwald-Lenum reports a $10 \%$ critical value of 78.36 and a $5 \%$ value of 82.49 . His tables imply a $P$ value of below 0.10 .

Overall, the empirical results of the paper show only partial convergence of policies among large subsets of the EU countries. In fact, for all the criteria laid down by the Maastricht Treaty, the number of shared common trends is greater than one, and for the real DM rates, long-term interest rates, and deficit/GDP ratios, the number of shared common trends is greater than the number of cointegrating relations. These results emphasize the need for greater policy coordination among the EU members. On the other hand, for a smaller collection of EU countries, there exists only a single shared stochastic trend in each system of real DM rates and long-term interest rates. This suggests a complete convergence of government policies among these countries. Based on this evidence, it is tempting to suggest that the following countries would form a successful EMU in the long-run: Belgium, Denmark, France, Germany, Luxembourg, the Netherlands, and the UK. We have insufficient data on Greece and Ireland but, from the results on real DM exchange rates and long-term interest rates, respectively, their prospects appear to be promising. In contrast, Italy, Spain, and Portugal seem to be in greater need of policy coordination with the rest of the EU countries.

\section{Conclusion}

In this paper, we have presented an analysis of cointegration among the 12 original countries of the European Union. Cointegration is a necessary condition for co-movement in the long run and therefore for a successful EMU over time. Our empirical results support the view that an EMU would not be successful for all 12 original EU countries unless long-run fiscal and monetary policies are aligned further. Our results are consistent with those of related studies that considered a subset of our EU countries and the same variables: MacDonald and Taylor (1991), Bayoumi and Taylor (1995) and Hafer et al. (1997).

In particular, our results are consistent with those of Hafer et al. (1997), who analyzed interest rates for Belgium, France, Germany, and the Netherlands. It would be interesting, following that paper, to decompose each system of variables into its transitory and common trend components and attempt to identify the specific common trends that drive each system of variables. This would provide insights as to which countries' common trends dominate a given system of variables. Based on 
this information, better policies might be devised. We leave this research project for future work.

It is important to emphasize that our suggestion for the specific countries to form a successful EMU is based purely on the statistical analysis of the economic data for the Maastricht criteria. The actual decision as to which countries were allowed into the EMU in January of 1999 has been made: Austria, Belgium, Finland, France, Germany, Ireland, Italy, Luxembourg, Netherlands, Portugal, and Spain. As has been the case with other currency unions, political considerations, rather than purely economic factors, probably weighed heavily in this decision; see Mussa (1997). The importance of political factors along with economic concerns has been stressed by Mundell (1997), who recommended an initial EMU including all the 15 EU countries.

The selection of countries for the EMU to start in January of 1999 includes Austria and Finland, which we did not consider in our analysis. As far as the other participating countries are concerned, our results indicate potential problems for Italy, Portugal, and Spain. Our study indicates that these countries may face problems over the long-run: potentially painful long-run policy adjustments and reforms seem necessary. On the other hand, our results suggest that Denmark and the UK could be part of a successful EMU, even though these countries have decided not to participate yet.

\section{Acknowledgements}

This research was supported, in part, by grants from the Social Sciences and Humanities Research Council of Canada to the first two authors. The authors are grateful to the editor and two referees for comments on earlier versions.

\section{References}

Ahn, S.K., Reinsel, G.C., 1990. Estimation of partially nonstationary multivariate autoregressive models. Journal of the American Statistical Association 85 (411), 813-823.

Anderson, T.W., 1951. Estimating linear restrictions on regression coefficients for multivariate normal distributions. Annals of Mathematical Statistics 22 (3), 327-351.

Artis, M.J., Taylor, M.P., 1988. Exchange rates, capital controls and the European system: assessing the track record. In: Giavazzi, F., Micossi, S., Miller, M. (Eds.), The European Monetary System. Blackwell, Oxford, pp. 185-206.

Bayoumi, T., Taylor, M.P., 1995. Macroeconomic shocks, the ERM and tripolarity. Review of Economics and Statistics 77 (2), 321-331.

Delors Report, 1989. Report on Economic and Monetary Union in the European Community. Office for Official Publications of the European Communities, Committee for the Study of Economic and Monetary Union, Luxembourg.

Eichengreen, B., Wyplosz, C., 1993. The unstable EMS. Brookings Papers on Economic Activity, Macroeconomics (1), 51-125.

Engle, R.F., Granger, C.W.J., 1987. Cointegration and error correction: representation, estimation and testing. Econometrica 55 (2), 251-276.

Hafer, R.W., Kutan, A.M., 1994. A long run view of German dominance and the degree of policy convergence in the EMS. Economic Inquiry 32 (4), 684-695. 
Hafer, R.W., Kutan, A.M., Zhou, S., 1997. Linkages in the EMS term structures: evidence from common trend and transitory components. Journal of International Money and Finance 16 (4), 595-607.

International Monetary Fund, 1995. International Financial Statistics (IFS) CD-ROM, September. International Monetary Fund, Washington, DC.

Johansen, S., 1988. Statistical analysis of cointegration vectors. Journal of Economic Dynamics and Control $12(2 / 3), 231-254$.

Johansen, S., 1991. Estimation and hypothesis testing of cointegration in Gaussian vector autoregressive models. Econometrica 59 (6), 1551-1580.

Johansen, S., 1994. The role of the constant and linear terms in cointegration analysis of nonstationary variables. Econometric Reviews 13 (2), 205-229.

Johansen, S., 1995. Likelihood-based Inference in Cointegrated Vector Autoregressive Models. Oxford University Press, Oxford.

Johansen, S., Juselius, K., 1990. Maximum likelihood estimation and inference on cointegration with applications to the demand for money. Oxford Bulletin of Economics and Statistics 52 (2), 169-210.

Karfakis, S.J., Moschos, D.M., 1990. Interest rate linkages within the European Monetary System: a time series analysis. Journal of Money Credit and Banking 22 (3), 388-394.

Maastricht Treaty, 1992. Treaty on Economic Union. Office for Official Publications of the European Communities, Luxembourg.

MacDonald, R., Taylor, M.P., 1991. Exchange rates, policy convergence, and the European Monetary System. Review of Economics and Statistics 73 (3), 553-558.

MacKinnon, J.G., 1996. Numerical distribution functions for unit root and cointegration tests. Journal of Applied Econometrics 11 (6), 601-618.

MacKinnon, J.G., Haug, A.A., Michelis, L., 1999. Numerical distribution functions of likelihood ratio tests for cointegration. Journal of Applied Econometrics 14 (5), 563-577.

Mundell, R.A., 1997. Currency areas, common currencies and the EMU. American Economic Review 87 (2), 214-216.

Mussa, M., 1997. Political and institutional commitment to a common currency. American Economic Review 87 (2), 217-220.

$\mathrm{Ng}$, S., Perron, P., 1995. Unit root tests in ARMA models with data dependent methods for the selection of the truncation lag. Journal of the American Statistical Association 90 (429), 268-281.

Osterwald-Lenum, M., 1992. A note with quantiles of the asymptotic distribution of the maximum likelihood cointegration rank test statistics. Oxford Bulletin of Economics and Statistics 54 (3), 461-471.

Reimers, H., 1993. Comparison of tests for multivariate cointegration. Statistical Papers 33 (4), 335-359.

von Hagen, J., Neumann, M.J., 1994. Real exchange rates within and between currency areas: how far away is the EMU? Review of Economics and Statistics 76 (2), 236-244. 